\title{
The Political Scientist as a Blogger
}

\author{
John Sides, George Washington University
}

1 n November 2007, I helped found a blog, The Monkey Cage, with two of my colleagues, David Park and Lee Sigelman. This site joined a nascent political science blogosphere that is now composed of at least 80 blogs (Farrell and Sides 2010). The goals of The Monkey Cage are to publicize political science research and use this research to comment on current events. Although blogging is a promising way for scholars to promote their work to a larger audience, political scientists have been slow to take up this medium. To be sure, blogging is not without its challenges, particularly in terms of the time and energy needed to maintain a site. But blogging can also have its benefits by not only helping political science reach a broader audience, but also aiding individual scholars' research, teaching, and service goals.

\section{HOW TO BLOG}

Becoming a blogger is easy. Platforms such as blogspot.com provide hosting space and design templates, with no money and little specialized expertise required. Once the blog is created, the central task is producing content in the form of blog posts. Few blogs are successful if they are not updated frequentlyideally, more than once a day. At The Monkey Cage, we average about 2.5 posts per day. A post may take anywhere between five minutes and two hours to write, depending on its content. Other avenues to blogging entail affiliating with websites that regularly publish academic perspectives. For example, Pollster.com, which is now a part of the Huffington Post, features several political scientists among its contributors. The difference, of course, is that a personal blog allows the blogger greater opportunities and freedom than may be available at established blogs. ${ }^{1}$

What should a blog post address? Writing regular blog posts is not necessarily easy. It takes time to find a voice and learn the kinds of topics and ideas that will appeal to a broader audience. One guideline should be obvious: avoid personal complaints about your life, commute, colleagues, discipline, and so on-topics that are perilous from a professional perspective anyway (Tribble 2005). Choose topics to which you can add value as a political scientist. This approach will distinguish your blog from other blogs about politics and from most pundits' commentary. You can summarize your research or the work of other scholars, analyze data, and make simple graphs that are understandable to a lay audience. Ideally, your posts should be pegged to current events, but topical commentary is not always necessary. Even when political science research is months (if not years) behind the news cycle, its findings can still be relevant. For example, although few pundits are still analyzing the 2008 election, their potted histories and stylized impressions of that time drive their present thinking about current events, making new research about the election topical. If your post disagrees with a pundit, all the better: nothing attracts readers' attention like a little conflict.
If producing a regular flow of posts is too time-consuming, consider recruiting other authors for your blog. The Monkey Cage has always been a group blog, which ensures fresh content as well as diverse perspectives and expertise that may even lead to debates within the group that we subsequently publish as well. Our current roster of regular bloggers has expanded to fiveHenry Farrell, Andrew Gelman, Joshua Tucker,Erik Voeten, and me-and includes scholars of American politics, comparative politics, and international relations. Many other scholars have served as guest-bloggers at our site-which is a good way to get one's feet wet. Although is possible to maintain a blog singlehandedly, we have found that a group format eases the task of producing a continuous stream of new posts.

Blogging also necessitates certain administrative chores: registering and maintaining a domain name (if necessary), designing the site's appearance, reviewing and publishing readers' comments, and deleting the inevitable spam from such interested readers as "Fat Loss 4 Idiots." These are very manageable tasks. Determining the name and appearance of the site can be a one-time decision. Managing the flow of comments takes only a small amount of time each day, especially if you are content to allow real comments to intermingle with spam.

Finally, every blog encourages attention to other blogs and websites that discuss related content and, hopefully, your posts. It is easy to be drawn in by what other people write, especially if they take issue with your perspective. Conversation that results from these disputes can actually be an asset: attention from online conversations among bloggers will usually help to build an audience. For lesser-known blogs, taking issue with an established blogger and thereby drawing a response will often help expand the pool of readers.

This sort of attention is largely how The Monkey Cage built its audience over time. Between November 2007 and December 2010, The Monkey Cage was visited by about 719,000 people and viewed over 2 million times. Approximately 1,500 people visit the site on any given weekday, 2,7oo people subscribe to our RSS feed, and over 6oo follow us on Twitter. The blog's content has been cited by Newsweek, the New Yorker, the New York Times, Salon, the Economist, the American Prospect, the Washington Post, and the Financial Times, among others-although, relatively speaking, The Monkey Cage remains a niche blog.

\section{BUT DO I REALLY WANT TO BE A NAZI SCUMBAG MORON?}

The ease with which one can begin blogging conceals the pitfalls that a blogger may encounter. First, blogging takes time. Many scholars feel burdened by their teaching, research, and administrative responsibilities and frequently lament a lack of time for research and writing. Clearly, maintaining a blog entails effort that could be spent on other pursuits. As a 
blog becomes more successful, it will naturally demand more time.

Second, although scholars typically want to publicize their ideas in books and journals, daily publication can be treacherous. The average blog post reflects quicker and more haphazard thinking, simpler (and even simplistic) analyses, and more ill-advised dudgeon than the typical academic article. There is no peer review to save you from mistakes, and once your mistakes are published, they cannot easily be removed from the public domain. Political scientist bloggers can be spectacularly wrong, as I was in predicting a 2008 presidential race between Mitt Romney and Hillary Clinton (Sides 2008a).

Third, if the purpose of the blog is to discuss academic research, scholars may soon learn that readers outside of the
It is not serious that a professional review lends its pages to this statistical nonsense. Have they lost their common sense? I wish Ross a sex change and moving [sic] to Saudi Arabia. He will be able to check his/her [sic] statistical associations in situ.

I find it amazing that this was published in a peer-reviewed journal. Does Ross have tenure at UCLA?

At my instigation, Ross kindly replied to these and other comments. None of the people who made the original comments chose to engage him on the actual substance of his research.

In other cases, readers' responses are even more ad hominem. Henry Farrell once wrote what seemed an innocuous post on public opinion about health care reform, leading one

\section{If the purpose of the blog is to discuss academic research, scholars may soon learn that readers outside of the academy or the discipline do not understand and sometimes willfully misunderstand findings. A discipline's theoretical perspectives and methodologies will often strike individuals outside of the field as wrong or even worthless, which can be surprising to scholars trained to believe that their methods are normal, even if problematic in certain ways.}

academy or the discipline do not understand and sometimes willfully misunderstand findings. A discipline's theoretical perspectives and methodologies will often strike individuals outside of the field as wrong or even worthless, which can be surprising to scholars trained to believe that their methods are normal, even if problematic in certain ways. A colleague and I once wrote a blog post and then an op-ed (Sides and Lawrence 2008) to discuss some research in which we combined a set of survey questions about respondents' positions on political issues to create a left-right ideological scale and then described the behavior of respondents in different ideological camps (e.g., the "far left," the "far right"). We encountered strong objections from individuals who believed that we were characterizing respondents in some absolute sense and thus implying that people on the "far left" were extremists (Morill 2008). When my coauthor and coblogger Henry Farrell defended the research on The Monkey Cage, most commenters were not persuaded (Farrell 20o8).

Fourth, readers' reactions can be vitriolic. Although scholarly discourse allows for strong disagreement, rarely are these differences expressed as bluntly or even profanely as they are on blogs, particularly in the comments that readers can leave, often anonymously. For example, I once wrote a short post (Sides 2008b) about an article by Michael Ross (2008), who argues that dependency on oil production, not Islam per se, restricts gender equality in the Middle East. Thanks in part to links from other blogs with larger audiences, the post attracted such comments as:

Systematically removing women's genatilia $[$ sic $]$ and imprisoning them for getting raped isn't obvious enough for Ross? reader to deduce his Irish ancestry and then e-mail him the following message, under the subject line "Nazi Scumbag Moron":

Henry,

Can a Mick be convicted of treason or just espionage? I'd play it safe and skedaddle back to Dublin. Who knows, if the Jacobins take DC, you might find yourself tarred and feathered or drawn and quartered.

Love,

Stan

Comments like these are, to be sure, the exception rather than the rule. If you have a thick enough skin, they are easy to ignore. A blogger can also take the time to moderate comments and enforce norms of civility. Regardless of how you react, it is important to be prepared for the occasional Stan.

A final pitfall is potentially worse than criticism: being ignored. Unless you are content to treat your blog as a diary, you will inevitably want someone to read your posts. But because there are many blogs-probably too many, with hundreds of millions by some estimates-it is difficult for any one blog to gain much prominence. The challenge of broad exposure is even greater for a political science blog, which will never dish out the fare that many readers want from blogs about politics: Talmudic parsing of the horse race during election season or red meat for their preferred partisan or ideological faction.

Even if academic bloggers target a more "professional" audience-for political science, this group might consist of 
politicos and journalists-they may again find themselves dismissed. Many of these professionals have succeeded without paying much attention to political science but nevertheless believe they possess considerable expertise in the area. Some of these individuals are actively hostile to political science, such as New York Times writer Matt Bai:

Generally speaking, political writers don't think so much of political scientists, either, mostly because anyone who has ever actually worked in or covered politics can tell you that, whatever else it may be, a science isn't one of them. Politics is, after all, the business of humans attempting to triumph over their own disorder, insecurity, competitiveness, arrogance, and infidelity; make all the equations you want, but a lot of politics is simply tactile and visual, rather than empirical. My dinnertime conversation with three Iowans may not add up to a reliable portrait of the national consensus, but it's often more illuminating than the dissertations of academics whose idea of seeing America is a trip to the local Bed, Bath \& Beyond. (2009)

Being misunderstood, criticized, or ignored may sound like nothing new for the average academic. At times, criticism or inattention is entirely warranted: every utterance that a political scientist makes is not transcendental wisdom. However, it is sometimes easier to countenance a critical reaction from peers than one from a lay audience. Even well-regarded scholars who devote significant time to crafting accessible blog posts may find that they receive little to no attention or deference because of their training and expertise.

\section{WHY BLOG?}

Despite the occasional frustration, blogging can be fun-in fact, this is probably the first and best reason to do it. Once blogging starts to feel like work, you are probably not long for the blogosphere. A second reason is that blogging can help scholars become better teachers and researchers.

At a minimum, content produced for a blog can often be incorporated into teaching. I illustrate many blog posts with graphs of data that I later paste into a PowerPoint presentation for the classroom. Readers who are academics can and do use these materials for their own teaching. Furthermore, students often want to connect class material to real-life politics, and blogging can help articulate these connections, since the nature of the medium tempts the blogger into addressing current events. For example, media coverage of health care reform, like coverage of many policy debates, often focused on what Barack Obama did or did not do, should or should not have done, and so on. Treating Obama as the focal point of the issue gave short shrift to a lot of political science, which emphasizes the limited powers of the presidency (e.g., Edwards 2003, Neustadt 1990) and the importance of multiple veto points within the separation of powers system (e.g., Krehbiel 1998). When I eventually complained about this reification of presidential power on The Monkey Cage (Sides 2009), I was able to later insert this complaint into a lecture to provoke a broader discussion about the presidency.

The temptation to blog about current events also encourages scholars to become generalists, an orientation that is useful for teaching. Doctoral training pushes scholars into subfields within subfields, but undergraduate and graduate teaching demand familiarity with diverse topics and literatures. Scholars of political behavior have to explain how a bill becomes a law. Scholars of nuclear disarmament have to explain counterinsurgency. This is where blogging comes in. Every political scientist is familiar with versions of these queries from friends and relatives: "Well, you're a political scientist. Tell me who's going to win the election." Or "Tell me how we're going to win this war." Or "Tell me why those jerks in Washington can't get anything done." These queries do not respect subfield boundaries, and neither do the questions frequently posed by students. Dimly remembered graduate courses may offer little help in answering these questions. Blogging, though hardly a ticket to deep knowledge and expertise, can force scholars to canvass relevant literature, formulate thoughts, articulate them in accessible language, and add any necessary caveats.

The aspects of blogging described thus far-daily posts on a wide array of topics, debates with truculent commenters, and so on-may seem anathema to conducting research. However, blogging can easily facilitate research. One challenge of scholarly work is finding the time to both do the research and write about the findings. Conference paper deadlines are helpful but occur too infrequently. Maintaining a blog essentially creates a daily deadline.

The key is to use the blog as a long-running test-drive of a research project. Blogging forces you to write, and writing, for better or for worse, is often synonymous with thinking. A blog is thus a convenient repository for half-baked notions and tidbits of analysis. Blogging may provide a reality check as commenters chime in with questions, objections, and suggestions, thereby leading you to refine a project further. Much of Red State, Blue State, Rich State, Poor State (Gelman et al. 2008) was previewed on Andrew Gelman's personal blog. John Quiggin, an economist and blogger at Crooked Timber, "book-blogged" his way to the entire manuscript for Zombie Economics (2010) by posting regularly on the ideas in each chapter and soliciting feedback from readers.

Allowing readers to peek at the seamy underbelly of research-hypotheses constructed and abandoned, clerical errors in data analyses, and so on-may seem ill-advised. The question is whether these costs are outweighed by the payoffs. Often, they will be. Moreover, other modes of developing research, such as the public presentation and posting of conference papers, have not only their own costs, but also, if anecdotes are to be believed, few payoffs in terms of helpful feedback. Blogs, if not an ideal forum for incubating research, may still prove more useful than any other existing approach.

\section{SHOULD JUNIOR FACULTY BLOG?}

Is blogging for the untenured? By dint of their relative youth, untenured faculty are often those most disposed to read and produce content online, but they may perceive blogging as professionally risky. One political scientist and prominent blogger, Daniel Drezner, did not receive tenure at the University of Chicago-a fact that cannot be directly attributed to his blogging but nonetheless may make junior faculty anxious (see Drezner 2005). 
At one level, skepticism about the time you spend blogging has an arbitrary quality. Because blogging is public, some may consider it a direct threat to research productivity. But why focus on the opportunity cost of blogging? This activity is far from the only thing that detracts from time devoted to research. Political scientist and blogger Chris Blattman makes this point well:

I average under 30 minutes a day blogging-less than most people would take to commute (I don't), practice an instrument (nope), or watch a TV show (don't even own one). Has anyone ever reflected, "A pity Bob didn't get tenure. It's a shame he lives in the suburbs and plays the piano. But it's that fourth season of 'Lost' that really screwed him"? (2009)

Nevertheless, it does not hurt to minimize the professional risks of blogging. Blogging will not substitute for good gent scholars to consume it all. Blogging about your research raises its visibility, which is a valuable result, given that your promotion depends upon your being well-situated in the discipline and enmeshed in a network of scholars who know you and your work.

The publicity that a blog produces may lead people outside of academia to perceive you as an expert. This awareness may spark requests for media interviews or solicitations from the popular press for pieces of writing. Although op-eds cannot take the place of peer-reviewed research or effective teaching, some departments and universities consider activities that reach a broader audience to be a service to the university.

Blogging can be a valuable service to the discipline as well. The easiest way to provide such a service is to publicize the work of other political scientists on your blog. Because the average scholarly article reaches only a small audience of aca-

\section{Allowing readers to peek at the seamy underbelly of research-hypotheses constructed and abandoned, clerical errors in data analyses, and so on-may seem ill-advised. The question is whether these costs are outweighed by the payoffs. Often, they will be. Moreover, other modes of developing research, such as the public presentation and posting of conference papers, have not only their own costs, but also, if anecdotes are to be believed, few payoffs in terms of helpful feedback. Blogs, if not an ideal forum for incubating research, may still prove more useful than any other existing approach.}

research or teaching in the minds of promotion and tenure committees, and untenured scholars are unwise to let blogging prevent them from completing necessary work. It may also be valuable to consult with senior colleagues before starting to blog. I followed this strategy, and the blessings of my senior colleagues were perhaps most evident in the decision of one, Lee Sigelman, to co-found The Monkey Cage and the willingness of several others to guest-blog from time to time.

Let us suppose that colleagues have given the blog the green light. Why do it? First, all of the benefits for teaching and research noted previously apply doubly to untenured faculty, who are not as experienced as senior faculty at developing course content and an active research agenda.

A second benefit for untenured faculty is publicity. Naturally, the mere existence of your blog does not mean that anyone will read it. If the blog is something that you want to gain attention, you will need to mention it to friends and colleagues, as well as e-mail other political science bloggers. It cannot hurt to add the blog to your CV under the heading of "other writing" or something similar. As long as your blogging is supported by your colleagues, you should promote your blog.

Once your blog has gained an audience, it will help make your name more familiar-a simple but important outcome in a growing field in which individual recognition, especially outside of your chosen subfield, can be elusive. Moreover, if you blog about your research, you will expand its impact. Too much research is currently being produced for even the most dili- demics, even a single blog post may increase this audience severalfold. In my experience, no scholar has objected to this kind of attention on The Monkey Cage-their work is already in the public domain, in any case, and so blog posts are not revealing state secrets. (However, it is always courteous to let someone know that you are blogging about him or her.) Thus, blogging can accrue goodwill for you within the scholarly community, which certainly cannot hurt when some of these people will be writing tenure letters on your behalf.

Blogging about others' research also builds another useful skill: appreciative thinking. Appreciative thinking means identifying and emphasizing the positive, which can be difficult. Graduate training is centered on critical thinking; after all, most dissertations are motivated by the belief that previous work is either wrong or incomplete. Academia is competitive, has too many scholars and too few faculty positions, and offers only occasional accolades at best. Academics can easily fall prey to jealousy, status anxiety, and resentment. When you regularly publicize others' research, blogging can serve as an antidote to these maladies. In the years since The Monkey Cage was founded, my attitude has changed. When I receive a scholarly journal and skim abstracts in search of blogging material, naturally, some articles interest me, while others do not. But now, I dwell much less on the latter and much more on the articles I do like and how they can be effectively summarized in a blog post.

Of course, any increased visibility or attention that a blog brings you is no ticket to tenure, lucrative job offers, or other 
glories. It may be difficult to prove that the blog has had any positive professional impact, just as it is difficult to prove that it has had any negative impact. This ambiguity is why the key to successful blogging is enjoying the time you spend on it. The expressive benefits will often outweigh the instrumental benefits. But these gains can be enough, especially if Conway's (2010) description of the prototypical academic blogger applies to you: "You are a nerd. You enjoy writing."

\section{TEARING DOWN PAYWALLS}

Academic knowledge is traditionally generated and disseminated in ways guaranteed to reduce its impact. Academics are given specialized training and learn to produce research that few others can understand. This research is then discussed at conferences attended only by other academics. The work is published, if at all, in journals available only to subscribers or in books that are rarely promoted widely. Even intrepid outsiders will stumble across it only infrequently.

This state of affairs should not satisfy us as political scientists. Interesting and important findings are gathering dust. Although not everyone who might benefit from reading political science will do so if given the opportunity, we should make our research available to people who want to read it and promote it vigorously so that some will discover that they want to read it. Political science needs public forums beyond the classroom that are readily available and accessible. Blogs are one such forum. If more political scientists turn to blogging, the discipline can become even more intellectually effervescent and pertinent to current political debates.

This argument is not simply naive and eager cheerleading, as the traffic statistics for The Monkey Cage attest. Even a niche blog like ours can attract enough attention-from more prominent bloggers, mainstream media outlets, and interested readers-to push political science into the spotlight and change public perspectives of how politics works. This aim is perhaps the most satisfying part of blogging: not merely convincing people that political science is relevant, but convincing people that its insights are valuable.

\section{NOTES}

I thank Henry Farrell, Seth Masket, Michael McDonald, and Brendan Nyhan for helpful comments.
1. Of course, scholars can maintain a public presence in other ways, such as providing important data via their websites-e.g., the NOMINATE scores available at Keith Poole's website (http://voteview.com) or the turnout statistics available at Michael McDonald's website (http://elections. gmu.edu/).

\section{REFEREN CES}

Bai, Matt. 2009. "Bloggers at the Gate." Democracy 12: 108-14.

Blattman, Chris. 2009. "Should Junior Faculty Blog?" Chris Blattman [blog], January 4. http://chrisblattman.com/2009/01/04/should-junior-facultyblog/.

Conway, Drew. 2010. “Ten Reasons Why Grad Students Should Blog." Zero Intelligence Agents [blog], June 8. http://www.drewconway.com/zia/ $? \mathrm{p}=\mathbf{2 1 7 4}$

Drezner, Daniel. 2005. “So Friday Was a Pretty Bad Day.” Daniel Drezner [blog], October 8. http://www.danieldrezner.com/archives/oo2353.html.

Edwards, George C., III. 2003. On Deaf Ears: The Limits of the Bully Pulpit. New Haven: Yale University Press.

Farrell, Henry. 2008. “The Netroots and the Far Left.” The Monkey Cage [blog], July 20. http://www.themonkeycage.org/2008/o7/the_far_left_and_ the_netroots.html.

Farrell, Henry, and John Sides. 2010. "Building a Political Science Public Sphere with Blogs." Forum 8 (3), article 10.

Gelman, Andrew, David Park, Boris Shot, Joseph Bafumi, and Jeronimo Cortina. 2008. Red State, Blue State, Rich State, Poor State: Why Americans Vote the Way They Do. Princeton, NJ: Princeton University Press.

Krehbiel, Keith. 1998. Pivotal Politics: A Theory of U.S. Lawmaking. Chicago: University of Chicago Press.

Morill, Barbara. 2008. "The 'Far Left' is the Mainstream.” Daily Kos [blog], July 17. http://www.dailykos.com/storyonly/2008/7/17/12526/4386/984/ 551257 .

Neustadt, Richard E. 1990. Presidential Power and the Modern Presidents: The Politics of Leadership from Roosevelt to Reagan. New York: Free Press.

Quiggin, John. 2010. Zombie Economics. Princeton, NJ: Princeton University Press.

Ross, Michael L. 2008. "Oil, Islam, and Women." American Political Science Review 102 (1): 107-23.

Sides, John. 2008a "Who Will Win the Nominations?" The Monkey Cage [blog], January 3. http://www.themonkeycage.org/2008/01/who_will_ win_the_nominations.html.

_. 2008b. "Does Oil Hurt Women's Rights?" The Monkey Cage [blog], June 10. http://www.themonkeycage.org/2008/o6/does_oil_hurt_womens_ rights.html.

. 2009. "What We Have Learned from the Health Care Debate." The Monkey Cage [blog], December 16. http://www.themonkeycage.org/2009/ 12/what_we_have_learned_from_the.html.

Sides, John, and Eric Lawrence. 2008. "Who Listens to Bloggingheads?" Los Angeles Times, July 13.

Tribble, Ivan. 2005. "Bloggers Need Not Apply." Chronicle of Higher Education, July 8. http://chronicle.com/article/Bloggers-Need-Not-Apply/45022/. 


\section{CAMBridge}

\section{JOURNALS}
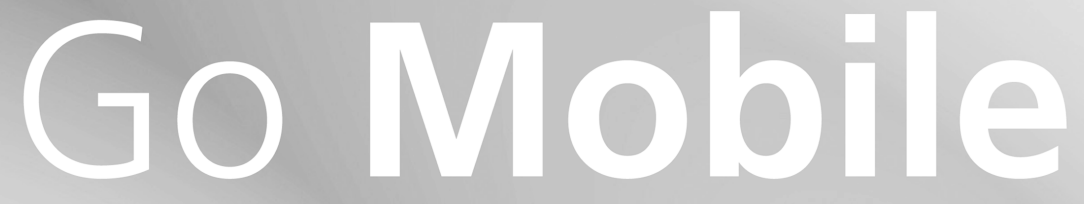

CJO Mobile $(\mathrm{CJOm})$ is a streamlined

Cambridge Journals Online (CJO)

for smartphones and other

small mobile devices

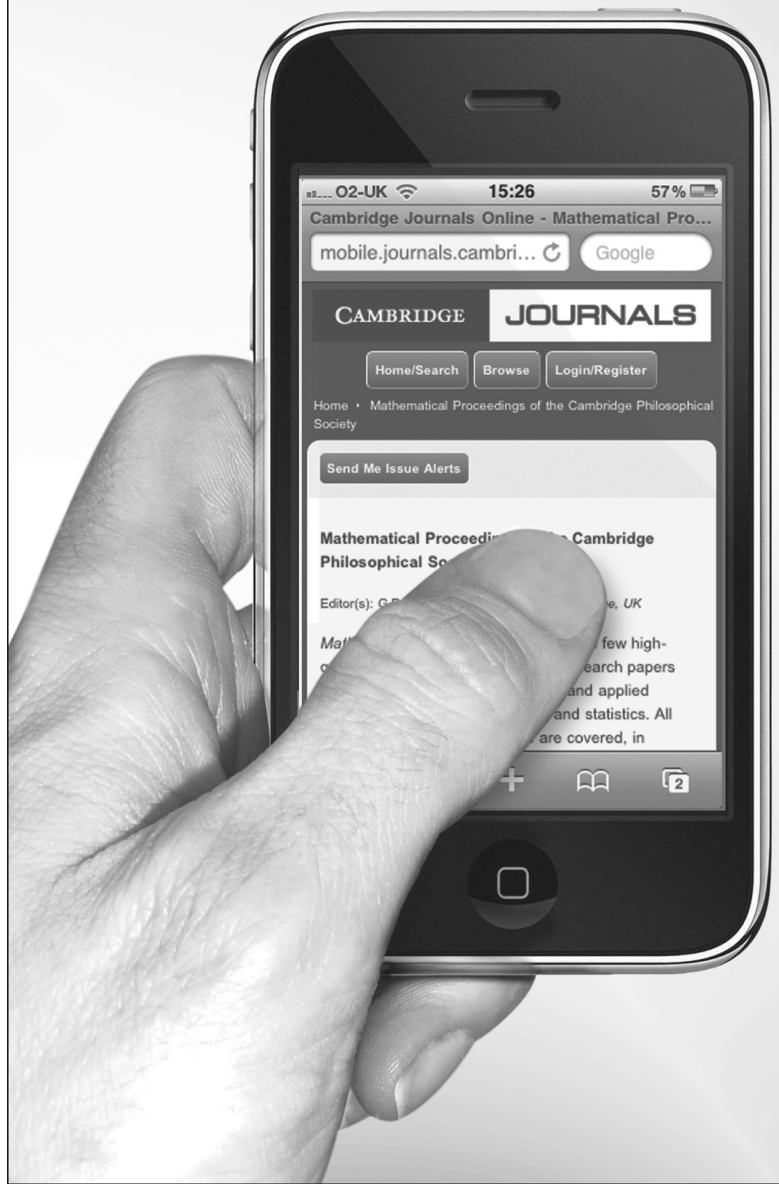

- Use CJOm to access all journal content including FirstView articles which are published online ahead of print

- Access quickly and easily thanks to simplified design and low resolution images

- Register for content alerts or save searches and articles they will be available on both CJO and CJOm

- Your device will be detected and automatically directed to CJOm via: journals.cambridge.org

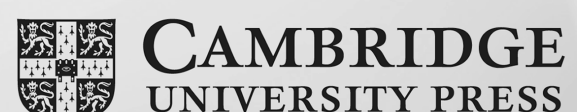
UNIVERSITY PRESS 